\title{
The Inclusion of Health Education Curriculum in Initial Teacher Education: Exploring the Possibilities
}

\author{
Moynihan, Sharon and Mannix-McNamara, Patricia \\ Department of Education and Professional Studies, Faculty of Education and Health \\ Sciences, University of Limerick
}

\begin{abstract}
Teacher education is critical to the successful implementation of health education in schools. This paper reports on the implementation of a pilot module in health education with initial teacher education students, which was offered on an optional basis to Physical Education graduate diploma students, in the University of Limerick, Ireland. Nine students decided to participate. The module was experiential and innovative in design. Pre and post tests were administered to students via questionnaire examining attitude, knowledge and experiences of Social Personal and Health Education. In addition a focus group was held with participants on completion of the module to gain a deeper understanding of their perspectives and experiences. The results indicate that as a result of exposure to health education, students reported increased confidence and interest in teaching SPHE in schools. Therefore, exposure to health education during initial teacher education has great potential as it can promote a positive disposition towards the subject. This paper challenges current provision of Health Education in initial teacher education and calls for a paradigm shift in policy, in this regard.
\end{abstract}

\section{Introduction}

Schools are recognised as important settings for health promotion (HP) $[1,2]$. They provide access to a wide audience and give the opportunity to provide health messages early in the lifespan. In so doing it promotes individual health behaviour gain in a sustained manner, thereby, increasing the potential health gain of a nation. Health education has significant influence on people's decision making, and perceptions of health. Behaviours that have a profound effect on health status, such as physical activity levels and dietary choices are established during the schooling years of many young people [3].

The emphasis of health promotion in schools has moved beyond the traditional health education class and into a more comprehensive settings approach. An effective school health education programme is one that combines health education with other health-promoting initiatives in the school, and involves parents, families and the community [4, 5, 6]. This approach signals a movement away from the health class per se, as the only place of information in relation to health. The World Health Organisation (WHO) have defined a Health Promoting School (HPS) as a school that is "constantly strengthening its capacity to be a healthy setting for living, learning and working by focusing on all the conditions that effect health" [7]. A whole school approach is multi faceted in nature and is advocated to be more effective than classroom only or single intervention approaches in achieving health and educational outcomes [8, 9].

The Irish education system has a specific post primary subject for health education entitled Social Personal and Health Education (SPHE). This subject has been a compulsory addition to the post primary curriculum for over a decade and while teacher inservice training is provided (40 hours professional development), it remains that pre-service teacher training provision is less than optimal. While implementation of the subject indicates policy commitment to health education, to do so with limited teacher education is clearly problematic, especially if a whole school approach is expected from schools. The Department of Education and Skills [10] policy statement clearly articulates that "all teachers are teachers of SPHE". Yet in many schools engagement is limited to only those teachers who are teaching SPHE. Those who are teacing SPHE are often the only ones nominated to attend SPHE in-service professional development. Therfore, appreciation and knowledge of the subject is not promoted across the whole staff which is incongruent with the policy statement that "all teachers are teachers of SPHE" [10]. Even more problematic is that many teachers continue to teach SPHE without any professional development at all [11].

Given that the majority of teachers have no exposure to this subject in their initial teacher education it is not surprising that they feel inadequately trained [12]. The authors advocate that more teacher education is required for teachers in order to deepen their confidence and skills in the area. In addition Irish teachers' knowledge of health promoting schools is also significantly limited. Irish policy has recommended implementation of SPHE 
within a HPS framework but this is hindered by lack of clarity on the abstract nature of the concept and practical applications involved [11].

The situation in Ireland is not unique as is evidenced by the literature which advocates for initial teacher education in health education globally [13]. Teacher education is a central factor linked to the quality of project implementation in schools [14]. Studies show that teachers who have received health promotion training tend to be involved more frequently in health promotion projects and have a more comprehensive approach to health education [15]. In order to make significant health and education gains through schools, there is a need for increased professional development of teachers [16].

Clift and Jensen [17] have advocated for the provision of appropriate teacher training in health related learning and teaching methods. The literature has recognised universities as key players in building teacher capacity in health education and has made recommendations that space be made on the curriculum for health promotion in pre-service teacher education [18]. In order for real change to occur in schools, universities need to be responsive to school needs. The teacher is a fundamental agent in school health promotion [19] and teacher training is thus a key player in the development of health education and health promotion in schools [13].

Teachers have varying perspectives on how they see their role in health promotion which is very much dependent on their subject but also their own epistemologies of teaching [14]. Exposure to health education/health promotion is critical in initial teacher education in order for a shift in teacher thinking so that all teachers perceive they have a role to play in the affective development of students [14]. The aim of this research was to seek to increase preservice teachers' knowledge and interest in teaching health matters and increase their competency in integrating a health promoting schools agenda into their practice. It also sought to address student teachers' attitudes toward SPHE and also, where relevant, to challenge deeply held perceptions of the subject.

\section{Methods}

A six week health education module was devised and implemented in the University of Limerick, in an effort to increase teacher education in the area. The module was offered to all students in their final semester of a post graduate diploma programme in Teacher Education (consecutive model) in the discipline of Physical Education. Nine out of a full cohort of twenty three students elected to participate in the module. The module arose following from a study that had identified the core competencies for health education teachers [20]. These competencies included; general content knowledge of health issues, pedagogical health content knowledge, promotion of teacher as a 'researcher', communication skills, willingness to participate in whole school approaches to health, as well as obtaining the skills necessary in planning, implementing and evaluating whole school approaches to health, knowledge of health curricula, and promotion of ethical thinking skills [20]. Having identified these competencies, it was then decided to create and pilot a module for initial teacher education that aimed to develop these competencies.

The emphasis on the module was to develop these knowledge, attitude and skills within the student teachers, through the content and pedagogy used as well as through the assessment of the module. The teaching and learning methods used throughout were experiential and modelled the pedagogy encouraged in Irish SPHE classrooms. Topics covered included; a critical examination of SPHE curricula, at Junior and Senior cycle; an exploration of the Health Promoting School framework; an investigation of the place of affective education in schools; awareness creation around available teaching resources and opportunities for further training. Content also specifically included; diet and physical activity, alcohol use, relationships and sexuality and bullying, There was a dual purpose in the way this content was handled; 1) to increase students content and pedagogical knowledge on the topic and 2) to heighten awareness of their own health behaviours. A reflective pedagogical approach was employed to enhance their awareness of their own health behaviour.

A mixed methods approach was employed for data collection. "The combination of both forms of data provides a better understanding of a research problem than one type of data alone" [21]. For the purposes of this research study, a pre and post test (questionnaire) was administered to participants as well as a focus group conducted on module completion. The student teachers also kept a reflective journal for the duration of their module studies which provided a deeper insight into their learning. For the purposes of this paper, the results from the questionnaires and the focus group will be discussed.

Questionnaire data were inputted into SPSS and descriptive analysis conducted on the data. The focus group was transcribed verbatim and pseudonyms given to the participants to protect their anonymity. The transcript was inputted into the software package MaxQDA and thematic analysis as per Boyatzi, [22] was conducted.

Ethical approval was sought and granted by the University of Limerick's Research Ethics Committee. 


\section{Results}

\subsection{Participant profile}

Six of the participants were female while the remaining three were male. The majority of students $(n=5)$ that took part in the module were between 23 and 25 years of age, one person was aged between 26 and 28 years and the remaining three participants were 29 years and over. Seven of the participants had no experience of the school subject at post primary level.

\subsection{Value of SPHE}

On a semantic differential scale in the pre-module questionnaire, participants were asked to rate how they perceived the value of SPHE (1 being extremely valuable and 5 being not at all valuable).

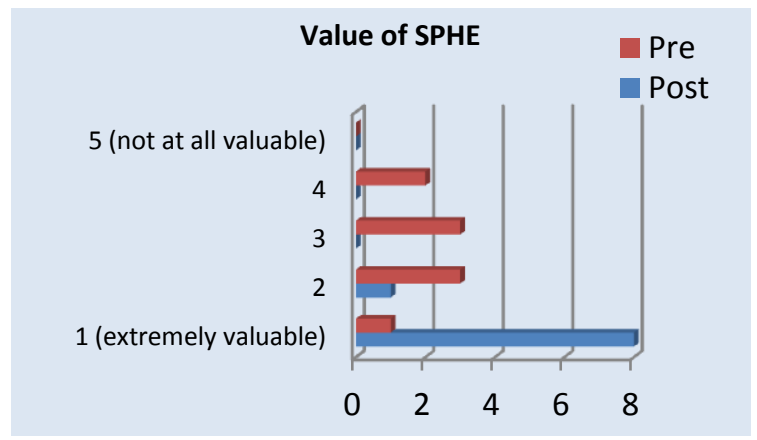

Figure 1. Value of SPHE

Only one person rated it as extremely valuable while three people rated it as 2 and another three students rated it as 3 on the scale. The remaining two participants rated it as 4 while no participant rated it as a 5(not at all valuable). When participants were asked to expand on their responses it appeared that students were not very sure of what the subject involved but expected it to be worthwhile, for example:

"I'm not very sure of what the subject entails" (Q.R. 2).

"I have limited knowledge of the subject but I expect it is extremely valuable" (Q.R. 4).

"I have no experience in SPHE but from talking to other teachers, students have alot to gain from taking part in the class" (Q.R. 7 ).

However, exposure to the module changed these ratings. When asked how valuable the students thought the subject SPHE was on module completion, eight of the participants rated it as 1 (extremely valuable) while one person rated it as a 2 on the 5 point semantic differential scale. When asked to further comment, the students spoke of the relevance of the subject to young people's lives.

"The relevance of SPHE components and young people is unbelievable" (Q.R. 1).

"Very important for children in today's society with so many issues affecting health" (Q.R. 4).

On completion of the module when participants were asked to describe their attitude toward SPHE, they were extremely enthusiastic and positive about the subject.

"Initially I had no experience of SPHE and now I realise the importance and the value it has within a school" (Q.R. 2).

"I thoroughly enjoyed the module. My attitude has definitely changed on SPHE to be honest. I never really rated $i t$, but now I feel it is so important in schools. More important than many other subjects that are on the curriculum" (Q.R. 6).

"A valuable module that should be covered in secondary schools to help and educate students about important issues" (Q.R. 9).

It is clear that exposure to SPHE during their initial teacher education promoted a positive disposition to the subject among the participants.

The theme of the value of SPHE also emerged during the focus group. Participants questioned why SPHE is one of the few subjects that is compulsory in all schools and yet is least valued in practice.

"It's actually compulsory in all schools and there are very few subjects that are that so why isn't more worth in it? Why isn't there more value in it?" (Adrian).

Suggestions that were put forward as to why this is the case. Firstly, the fact that it is not an examinable subject was discussed. "It's not examined, it's not valued" (Amy). They felt that most teachers in schools feel their role is to "get the grades in the junior cert and leaving cert" (Mary) and part of the reason for this was "that's how they are known as a good school" (Amy). They compared it to their own subject, Physical Education which they believed is also undervalued,

"People's perceptions of it...students don't learn a thing. We don't have much preparation but there's actually a lot more to it than people actually recognise" (Tim).

The suggestion was put forward that it is up to the individual teachers to make the subject worthwhile 
and create value in SPHE. Another reason suggested for the lack of status afforded to SPHE was the coercing of teachers into teaching the subject.

"whereas if the principal actually asks volunteers to teach it, they are obviously going to value it more" (Katie).

When asked whether they would volunteer for the teaching of SPHE, this was met with a chorus of positive affirmations. Participants also articulated concern that anyone can teach SPHE and there is no specific qualification for the subject which also contributes to the lack of value associated with the subject.

"I know people in our course that went on teaching practice and if someone asked them what is your second subject they were always embarrassed to say SPHE as their second subject" (Michelle).

\subsection{Confidence teaching SPHE}

Before undertaking the module students were asked to rate on a 5 point semantic differential scale, how confident they would be to teach SPHE in school upon graduation.

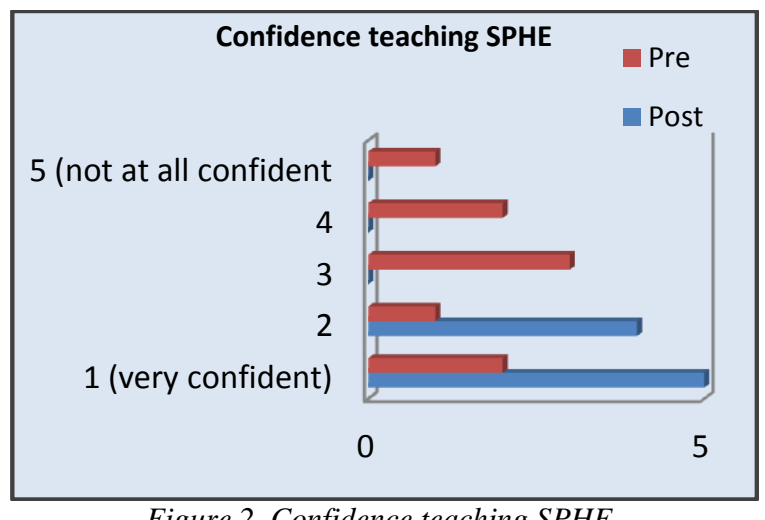

Figure 2. Confidence teaching SPHE

Two people picked 1 (very confident) while one person said 5 (not at all confident). Of the remaining six students, one person rated it a 2 while three participants rated it a 3 and the two participants rated it a 4 . When students were asked to describe their attitude toward SPHE, there was a mixed response. Four of the responses were centered on the fact that they felt uneducated on the topic and thus unable to adequately describe their attitude toward the subject.

"I am quite uneducated on the topic, thus leaving me with a weak opinion and not much of an attitude" (Q.R. 3).

"I don't know enough about it at the moment" (Q.R. 8).
Other attitudes included that it was an important subject in order to educate students holistically and also that it was a class that offered a lot of potential;

"I believe SPHE is a great interactive class which offers students and teachers a chance to explore issues which they will never get to do again in an ed. setting. I think the teachers input and prep is as important if not more so than the student" (Q.R. 7).

One student alluded to the fact that this class is often "labelled as a free class" thus addressing the lack of status afforded to the subject at post primary level.

However, exposure to the module had quite an impact on their responses with five students rating their confidence as 1 (very confident) while the remaining four students rated their confidence as 2 (confident) on module completion.

\subsection{Planning to teach SPHE}

Prior to exposure to the module eight of the participants said they planned to teach SPHE once qualified while one person was unsure. It became apparent when participants were asked to further comment on this question the main reason they planned to teach SPHE was in order to gain employment

"If needed I will, however geography and PE would be my main subjects as I am more confident in teaching them" (Q.R. 1).

"It will stand to me once I'm qualified and seeking employment" (Q.R. 2).

Teaching it, for some, appeared "unavoidable", as they believed "all teachers are being asked to cover some form of SPHE” (Q.R. 5). Participants were asked the same question on completion of the module and all of the participants said they plan to teach SPHE as a subject once qualified. The reasons cited differed from the pre module questionnaire and were now based on the value of the subject as well as the enjoyment generated from exposure to the module rather than the initial less altruistic motives of gaining employment post-graduation.

"The enjoyment I got in the class and the difference it could make to students" (Q.R.3 ).

"This class, as see how important it is" (Q.R. 4).

\subsection{Importance of pre-service exposure to health education}

The importance of exposure to health education in pre-service teacher education became apparent from the participants own discussions during the focus 
group. They voiced concern about teachers not being exposed to SPHE during pre-service training arguing that exposure can have an important effect on a teachers' attitude and disposition to teaching the subject,

"... if I had gone in teaching without doing this, I might not have understood how important it actually is when you delve into it" (Sally).

"I would have assumed that SPHE was a farcy subject but after doing the course you do realise how important it is but we are like the people who are uneducated in schools who are the teachers" (Amy).

"I think that if teachers are teaching SPHE it should be an accredited subject" (Michelle).

The students clearly indicated increased comfort and confidence in teaching SPHE post exposure to it during their pre-service education, arguing that it was important teachers were educated on this subject.

\subsection{Participation in the module}

When asked why they had decided to participate in the module, in the pre-module questionnaire, all of the participants cited reasons attributable to gaining employment in the future,

\section{"...to enable me to teach another subject" (Q.R. 2).}

"Something extra to put on the CV Making me more employable having a third subject. Convenient that it is during term time" (Q.R. 3).

"To get as many 'add ons' with my qualification as possible, I've paid a lot of money to be in UL, so need as many qualifications as possible" (Q.R. 8).

When participants were asked what they hoped to gain from the module, a range of answers were received which included increased knowledge, skills and experience of the subject as well as greater understanding of the subject and its value.

Participants were asked to what extent each of the module objectives had been met. Each objective was put on a seven point sematic differential scale, ranging from 1 - objective fully met to 7 - objective not at all met. Participants identified that all the objectives had been sufficiently met. All nine of the participants felt that three objectives had been fully met and rated them as a 1 on the semantic differential scale; 1) To explore various experiential learning and teaching methodologies for SPHE; 2) To enable students to critically reflect on their role as a teacher of the whole person and not just a teacher of Physical Education and 3) To promote discussion on the place of SPHE within schools. While seven participants chose 1 for the remaining three objectives and two participants chose 2 ; 4) To become familiar with the SPHE syllabus and health promoting school framework; 5) To develop students self awareness of their own health behaviour and 6) To develop students critical thinking skills in terms of the Irish education system.

The students were asked their thoughts on the module, post completion and all of the comments received were positive in nature.

"The module was so effective in instilling the core values of SPHE, methodologies used were novel, new and entertaining. Learning these new ideas was great and opened my mind up to thinking of new methodologies to use in SPHE" (Q.R. 1).

"Very interesting, very informative, very enjoyable, very fun" (Q.R. 7).

"I really enjoyed the module and feel confident going to a school to teach it (if I have the opportunity)" (Q.R. 2).

Two of the participants alluded to the idea that the module should be extended in length,

"I would have loved if we had a few more weeks covering other topics" (Q.R. 2) and "more than 6 weeks would be beneficial" (Q.R. 6).

On completion of the module students identified having increased "confidence in teaching SPHE", "greater insight into the process of teaching it", "better ideas and content knowledge", recognition of "the importance of discussion in an SPHE class which you get from not looking at a book all of the time, using interesting methodologies" and "the importance of the role we play in children's development".

\subsection{Learnings from the module}

A variety of answers were given when they were asked, "What did you learn on this module?" Some of the participants cited content knowledge including curriculum and syllabus knowledge.

"I learned exactly what was in it, what were the strands were and what you should be teaching" (Amy).

Classroom based pedagogy was also discussed and the various methods used, where students felt that the ideas presented in this regard were "interesting" (Michelle) and the "ideas were brilliant that you can definitely use" (Amy). The students also felt the assessment of the module also contributed to their 
learning because they had to create lesson plans that would be shared with everyone and also gain experience teaching a lesson.

"[I liked] the assessment part of it....initially I was like grrr but if you do put alot of effort into the four lessons, everybody can take it and use it" (Mary).

When participants were asked to finish the sentence 'I thought the course was...' the words used were 'helpful', 'effective', 'delivered very well', 'educational', 'enjoyable', 'informative', 'valuable', 'enjoyable', 'caring' and 'inclusive'. They also indicated that the enthusiasm of the teacher educator is really important to the success of the subject,

"it rubs off on us. The enthusiasm is infectious....caring in content and caring in process" (Adrian).

Other outcomes listed included "confidence in teaching SPHE", "greater insight into the process of teaching it", "better ideas and content knowledge", "pedagogy", "the importance of discussion in an SPHE class which you get from not looking at a book all of the time, using interesting methodologies" and "the importance of the role we play in children's development".

\subsection{Participant Recommendations}

Participants indicated the module was too short and if it was to be done again, it should be lengthened, as there is alot to cover. "It seemed a bit rushed for me" (Cathal). "I think personally a bit longer" (Michelle). A suggestion was put forward that a course during the summer could be considered as part of continuous professional development for teachers however, doubts were raised as to whether teachers would attend. The recommendation made was that it would be better to conduct the training during pre-service as you can influence their attitude toward teaching it,

"Ye would be aswel to make the courses here where you already have the people coming through that you already have getting them in the mood to want to teach it and to teach it properly" (Amy).

"Why can't you incorporate it into a degree?" (Cathal).

Participants also commented on the numbers involved in the course and felt that for optimal learning, it should be kept to small numbers

"I like the way there are round tables, you couldn't be in the lecture theatres. It was so effective when we had 9 students" (Amy).
The answer was unanimous when asked if the course should continue as all answered affirmatively. They felt that a refresher course should be run and felt "because we all had such a good experience that we would come again" (Mary).

\section{Discussion}

Pre-service teachers' exposure to health education elicited a positive response in this study. Participants indicated that their attitude changed to the subject once they became knowledgeable about what the subject entailed. The authors argue that in-service professional development of 40 hours is not enough to support or encourage all teachers to perceive they have a role in SPHE [18]. Generally, it is only those teachers who have agreed to teach SPHE attend this professional development. Therefore, opportunities to open up the minds of other teachers to the possibility of teaching the subject, or even supporting it through cross curricular links is lost through lack of exposure to the content and ethos of the subject. The literature identifies that teachers who have exposure to SPHE are more positively disposed to the subject [23].This is why students need to be exposed to health education earlier, in fact, it should be done in initial teacher education. This is important, to promote a positive disposition to the subject and also to encourage them to see the role they can play in the affective development and holistic education of their students in school.

The module was taught using experiential teaching methodologies and this was done to raise students' awareness of using these methodologies. It is also important because teacher educators should model the pedagogies they promote among their students. If experiential learning methodologies are promoted for the classroom, teacher educators should follow and model best practice in their teaching [24].

Through participation in this module, students came to appreciate the value of health education and also the incorporation of the broader health promoting schools approach in their teaching. In order for student teachers to conceptualise what a Health Promoting School may look like, universities need to become health promoting settings, themselves [25]. It appears, however, that universities and colleges of education are faced with the same challenges presented to schools, in order to make their setting health promoting. These challenges include, time and resource constraints, competing curricula demands and a lack of shared commitment to the concept [25]. Teacher training colleges and universities need to work to overcome these barriers, to create health promoting universities that provide an example for student teachers [25]. Student teachers need to experience an alternative to what their own schooling experience may have been, in order for them to want to become involved in 
organisational change as regards HP during their teaching career [25].

The majority of the students had no previous experience of the subject at any level and therefore, the majority were unaware of its benefits. Upon module completion however, students also saw the role they had in the overall development of the child and not merely as a subject specialist. More work needs to be done in initial teacher education around teacher identity, in order for student teachers to see their future roles as educators of the whole person and not limiting themselves to just their subject specialism. Before the module commenced the main reason the students planned to teach the subject was to gain employment, however, on completion, the reasons became more altruistic in nature including the value that school children could gain from the subject. It is evident from the data that exposure to SPHE changed the attitude of these pre-service teachers in a positive way.

The lack of status afforded to SPHE was a particular concern of the student teachers and they believed SPHE required a professional qualification. By including SPHE on the teacher education curriculum, it raises the profile of SPHE and enthuses students about the subject, so that when they are employed in schools, they can advocate for SPHE and in doing so, raise the status of SPHE within schools. PE and SPHE are both concerned with health and well-being. Both are suffering from a lack of status in schools. The participants in this study were pre-service PE teachers and they believed that the content was definitely relevant to their future roles as PE teachers, indicating significant overlap with their own subject. The authors advocate that a shared model of implementation of SPHE and PE would be a positive move forward where cross curricular links could be more easily facilitated. This would further encourage collaboration among school staff.

Through completion of the module participants' confidence in teaching the subject increased and they became more open to teaching the subject in schools [13]. Universities need to prioritise health education for teacher training and it needs to be integrated into the pre-service teacher education curriculum [18]. Teaching an introductory module of SPHE needs more time allocation than six weeks as there is a broad range of content and pedagogy to be explored, as identified by participants. This pilot module was simply a taster for students. There are differing opinions as to whether HP should feature prominently in compulsory modules or if HP should be integrated as an interdisciplinary principle of teaching and learning [25]. This is, however, very much context dependent.

The authors contend that health education on the Irish teacher education curriculum should feature as at least one full module for twelve weeks in duration and should be offered to all students. In this way it would at least fulfil the policy directive that "all teachers are teaches of SPHE" [10] and at minimum all are aware of the subject, its content and pedagogy. This would also open up the discursive spaces for teachers to be able to make cross curricular links between their subject and SPHE which is also an underlying principle of SPHE currently. However, the authors also argue that teaching SPHE requires a certain disposition and interest that all teachers may not possess. Therefore, while the module of twelve weeks is recommended for all pre-service teachers, an additional opportunity to specialise for the people who are interested in teaching the subject should also be provided. This would require a paradigm shift amongst policy makers, such as the Department of Education and Skills and the Teaching Council, in which they would recognise and promote SPHE as an important subject requiring an initial teacher education qualification. In order for SPHE to gain parity of esteem amongst post primary teachers it requires a professional qualification. The optimal situation would be that SPHE is streamed within undergraduate teacher education provision so that students engage with SPHE as a subject in tandem with their cognate discipline.

\section{Conclusion}

A positive disposition towards SPHE was encouraged and promoted by providing student teachers with exposure to health education during initial teacher education. Therefore, the authors suggest that health education should be incorporated into all teacher training courses in order to raise student teachers' awareness of the health education curriculum as well as encouraging broader involvement in the HPS initiative. Students should have exposure and the opportunity to experience personally, the active methodologies that are encouraged in health education, so as to increase their confidence and skills in experiential and active learning. For too long, pressure has been put on schools to solve the health crises of society, without effectively supporting teachers in this regard. Teacher education has a key role to play here and the first step must be to make space on the teacher education curriculum for health education and holistic education, and for teacher education to move from lip service to real and effective practice.

\section{Limitations}

No generalisations can be made due to the small sample size in the study. Another limitation was that the module was only conducted with one subject discipline of teachers, who potentially are more 
positively exposed to health education by the nature of their discipline of Physical Education. The module should be conducted with student teachers across various subjects in initial teacher education to see if similar results are achieved.

\section{Acknowledgement}

The research was funded by the Irish Research Council.

\section{References}

[1] Mukoma, W \& Flisher, A.J. (2004) 'Evaluations of health promoting schools: a review of nine studies', Health Promotion International, 19(3), pp. 357-368.

[2] St Leger, L., Young, I., Blanchard C., Perry, M. (2010) Promoting Health in Schools: from Evidence to Action. An International Union for Health Promotion and Education (IUHPE) publication,

http://www.iuhpe.org/index.html?page=516\&lang=en\#sh_ advevid. Accessed on: 30 June 2013.

[3] Mohammadi, N.K., Rowling, L. And Nutbeam, D. (2010) 'Acknowledging educational perspectives on health promoting schools', Health Education, 110(4), pp.240-251.

[4] Seffrin, J.R. (1990) 'The comprehensive school health education curriculum: closing the gap between state-ofthe-art and state-of the-practice', Journal of School Health, 60(4), pp. 151-156.

[5] Young, I. (1993) 'Health promoting schools: healthy eating policies in schools - an evaluation of the effects on pupils' knowledge, attitudes and behaviour', Health Education Journal, 52(1), pp.3-9.

[6] Denman, S. (1994) 'Do schools provide an opportunity for meeting the Health of the Nation targets?' Journal of Public Health Medicine, 16(2), pp.219-224.

[7] World Health Organisation (2013) School and youth health, Available at: http://www.who.int/school_youth_health/gshi/hps/en/index .html Accessed on 10 June 2013.

[8] Stewart-Brown S. (2006) 'What is the evidence on school health promotion in improving health or preventing disease and, specifically, what is the effectiveness of the health promoting school approach?' WHO Regional Office for Europe; p.26 Available at: http://www.euro.who.int/document/e88185.pdf (accessed on 02 July 2013).

[9] Moon, A.M., Mullee, M.A., Rogers, L., Thompson, R.L., Speller, V. and Roderick, P. (1999) 'Helping schools to become health promoting environments - an evaluation of the Wessex Healthy Schools Award', Health Promotion International, 14(2), pp.111-122.

[10] Department of Education and Science (2000) Social Personal and Health Education, Government Publications, Dublin.
[11] Burtenshaw, R. (2003) Report from the Review of Social, Personal and Health Education at Junior Cycle by the SPHE Support Service Post-Primary, available at: http://www.sphe.ie/review2.pdf Accessed 21 May 2013.

[12] Geary, T. and Mannix McNamara P. (2003) Implementation of Social, Personal \& Health Education at Junior Cycle: National Survey Report, University of Limerick, Limerick.

[13] Jourdan, D., Samdal, O., Diagne, F. Carvalho, G. (2008) 'The future of health promotion in schools goes through the strengthening of teacher training at a global level', Global Health Promotion, 15(3), pp. 36-38.

[14] Jourdan, D., Mannix McNamara, P., Simar, C., Geary, T. and Pommier, J. (2010) 'Factors influencing the contribution of staff to health education in schools', Health Education Research, 25(4), pp.519-530.

[15] Simar, C., Jourdan, D., Pizon, F., \& Barnoin, J. (2007) Teacher's Professional Positioning in Relation to a Health Education Program. Communication at the 2007 World conference of IUHPE, Vancouver, Canada.

[16] St. Leger, L. (2004) 'What's the place of schools in promoting health? Are we too optimistic?', Health Promotion International, 19(4), p.405-408.

[17] Clift, S. \& Jensen, B.B. (2005) The Health Promoting School: International Advances in Theory, Evaluation and Practice. Danish University of Education Press, Copenhagen.

[18] Mannix McNamara, P., Moynihan, S., Jourdan, D. \& Lynch, R. (2012) 'Pre-service teachers experience of and attitudes towards the teaching of Social Personal and Health Education', Health Education, 112(3), pp.199-216.

[19] St Leger, L. (1998) 'Australian teachers' understanding of the health promoting school concept and the implications for the development of school health', Health Promotion International, 13(3), pp.223-235.

[20] Moynihan, S., Paakkari, L., Valimaa, R., Jourdan, D. and Mannix McNamara, P. (in press) Teacher competencies in Health Education: what do the experts say? Health Promotion International.

[21] Creswell, J.W. (2005) Educational Research: Planning, Conducting and Evaluating Quantitative and Qualitative Research, 2nd ed., Pearson Prentice Hall, New Jersey.

[22] Boyatzis, R. (1998) Transforming qualitative information: Thematic analysis and code development, Sage, Thousand Oaks, CA. 
[23] Nic Gabhainn, S., O' Higgins, S. and Barry, M. (2010) 'The implementation of social, personal and health education in Irish schools', Health Education, 110(6), pp.452-470.

[24] Lunenberg, M., Korthagen, F. and Swennen, A. (2007) 'The teacher educator as a role model',

Teaching and Teacher Education, 23(5), pp.586-601

[25] Flaschberger, E. (2013) 'Initial teacher education for school health promotion in Austria: Does it support the implementation of the Health Promoting School approach?' Health Education, 113(3), pp.216-231. 